using deep inferior epigastric artery perforator flap is one of the commonly performed procedures. ${ }^{[1]}$ The donor vessels for the flap are either the internal mammary artery or its perforator and the thoracodorsal vessels. The internal mammary perforator's size is not predictable also access to internal mammary vessels need removal of costal cartilage and is technically difficult. In our experience, the thoracodorsal vessels are more commonly used for anastomosis of the flap pedicle due to their calibre. These vessels are encountered and can be protected with care during the axillary dissection.

After the anastomosis, we prefer to keep a suction drain in the breast under the flap and in the axilla. The axillary drain is loosely anchored to the chest wall away from pedicle to avoid inadvertent pulling of the pedicle. Following the flap transfer and successful anastomosis, the most important part is the avoidance of any external pressure over the site of the anastomosis. Till the patient is being shifted to the post-operative ward, they are generally accompanied by a member of the reconstructive team, but subsequently, a reliable method of protecting the anastomosis from the external pressure is desirable. Many innovative ideas have been described in the literature for the similar purpose (avoiding pressure over flap pedicle) depending on the site of the tissue transfer and the site of the

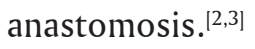

\title{
Simple way of splinting the arm following vascular anastomosis in the axilla
}

Sir,

Breast reconstruction is a common procedure after ablation of breast cancer in the western world and is slowly gaining acceptance in India. Of the reconstructive options, microsurgical reconstruction of the breast

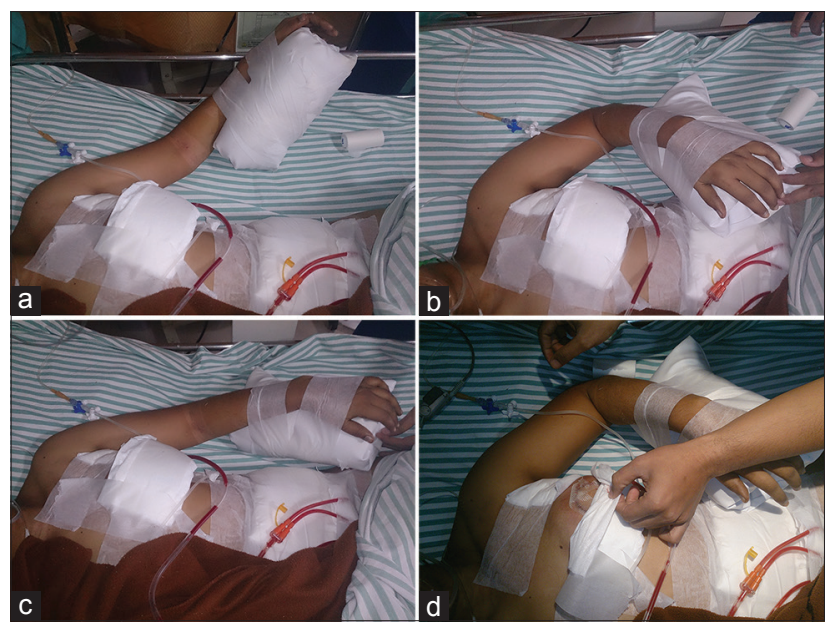

Figure 1: (a) Small pillow (big well-spread cotton roll/thick foam) is anchored to the forearm and the hand with paper plasters. The support should start just below the elbow on the volar aspect and should support the hand as well. (b-d) Once applied, it supports the arm away from the chest wall and prevents it from coming anywhere close to the axilla in any position of the hand. This splinting is necessary only for a few days, and it does not interfere the monitoring of the free flap 
We use a simple technique to reliably splint the arm away from the body. A small pillow is folded and is anchored to the forearm and the hand with paper plasters [Figure 1a]. The paper plaster makes sure that, though loosely plastered around the forearm, it prevents movements of the padding from its place. This splints and supports the arm away from the body irrespective of the position of the arm [Figure 1b-d]. These patients are usually under mild sedation for pain relief post-operatively. This technique reliably splints the arm away, and there is no worry about the support moving away with patient's movements. As it is secured well, there is no fear that the support itself will move into the axilla and cause pressure. The patient can keep the hand in any position comfortably. Another usual problem, if the patients are asked to maintain a particular position of the arm in the bed, is muscular strain causing pain around the shoulder and the neck. With the splint on, patients are very comfortable and are allowed free movement of the concerned arm. After the initial application, it usually does not need any attention and is generally removed on the $3^{\text {rd }}$ or $4^{\text {th }}$ day following the surgery. Flap monitoring is unhindered as there are no straps around the chest [Figure 1d].

\section{Financial support and sponsorship}

Nil.

\section{Conflicts of interest}

There are no conflicts of interest.

\section{Pravin H. P. Kumar, Vijay Dattatrya Kadam, Sushil Nahar, Rahul Krishnarao Patil, Ashok Raj Koul}

Department of Plastic and Reconstructive Surgery, Sparsh Hospital for Advanced Surgeries, Bengaluru, Karnataka, India

Address for correspondence: Dr. Rahul Krishnarao Patil, Department of Plastic and Reconstructive Surgery, Sparsh Hospital for Advanced Surgeries, Infantry Road, Bengaluru - 560 001, Karnataka, India. E-mail: doctrahul@yahoo.co.in

\section{REFERENCES}

1. Parrett BM, Caterson SA, Tobias AM, Lee BT. DIEP flaps in women with abdominal scars: Are complication rates affected? Plast Reconstr Surg 2008;121:1527-31.

2. Buford GA, Trzeciak MA. A novel method for lower-extremity immobilization after free-flap reconstruction of posterior heel defects. Plast Reconstr Surg 2003;111:821-4.

3. Venkataramani H, Jain DK, Sabapathy SR. A useful modification of the plaster backslab to off-load pressure from reconstructions of the heel and elbow. Indian J Plast Surg 2012;45:588-9.
This is an open access article distributed under the terms of the Creative Commons Attribution-NonCommercial-ShareAlike 3.0 License, which allows others to remix, tweak, and build upon the work non-commercially, as long as the author is credited and the new creations are licensed under the identical terms.

\begin{tabular}{|l|l|}
\hline \multicolumn{2}{|c|}{ Access this article online } \\
\hline Quick Response Code: & Website: \\
\hline & www.jps.org \\
\cline { 2 - 2 } & DOI: \\
\hline
\end{tabular}

How to cite this article: Kumar PH, Kadam VD, Nahar S, Patil RK, Koul AR. Simple way of splinting the arm following vascular anastomosis in the axilla. Indian J Plast Surg 2017;50:116-7.

๑) 2017 Indian Journal of Plastic Surgery | Published by Wolters Kluwer - Medknow 